\title{
Applying a complex manufacturing process to a specific product
}

\author{
Jozef Trojan ${ }^{1}$, Peter Trebuňa ${ }^{1}$, Marek Mizerák ${ }^{1}$ \\ ${ }_{1}$ Technical University of Košice, Faculty of Mechanical Engineering, Institute of \\ Management, Industrial and Digital Engineering \\ Park Komenskeho 9, Košice, Slovakia \\ jozef.trojan@tuke.sk \\ peter.trebuna@tuke.sk \\ marek.mizerak@tuke.sk
}

\begin{abstract}
Annotation: The article contains description and construction of the finished product, in our case it is the construction of the rear seat for the Ford car. We begin to solve the complex production process of our product by drawing up a production-assembly diagram, where we can see the individual parts of which it consists. Using the longest branch in this diagram we calculate the average assembly time and consequently the coefficient of concurrency. We will use the data to build a tree diagram (chronogram).
\end{abstract}

\section{Introduction}

Production is a business process where inputs are transformed into outputs. By inputs we understand production factors and the output from production is a specific product. Production of goods, including preparation of goods and services; serves to meet human needs. Production is a part of the transformation process of a company - a concrete transformation of production factors (inputs) into products (outputs) - a production process. Production is the main activity of the enterprise. An enterprise may have one, two or more main activities.

Production in its broadest sense means the production of goods, including the preparation of realized goods and the provision of services. Therefore, they serve the general satisfaction of human needs. That scope narrows the notion that production is an important function of an undertaking producing goods for primary or final consumption. Productive means only work that creates specific material products.

Production in the narrowest sense means only production as part of the transformation process, i.e. concrete conversion of production factors into products. This transformation takes place as a manufacturing process, which consists of a range of working, automatic and natural processes and is limited by the time interval at which the initial inputs are converted into a product [1]. 


\section{Description and composition of the finished product}

Our finished product, for which we decided to build a new workplace, is the rear seat construction for the Ford EcoSport (Figure 1).

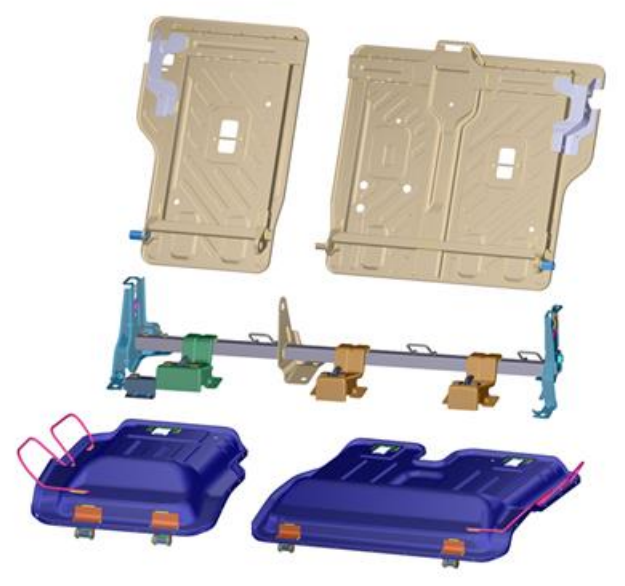

Figure 1 - Rear seat structure

As can be seen in Figure 2, it is the production of the entire structure, not just the part. The seat consists of five basic parts: the armrest, which is divided at $60 \%$ to $40 \%$, as well as the seat part is divided at a given ratio and an important part is the support rod, which serves us to connect the armrest to the seat, but mainly allows the rear armrest to be folded down to expand our storage space. The individual parts are composed of a plurality of parts or assemblies, which have been produced by successive operations of joining, riveting, spot welding, MAG welding, or combined spot and MAG welding in automated welding machines. After each operation, a check is carried out in order to achieve the lowest possible fraud and to meet all the quality requirements [2].

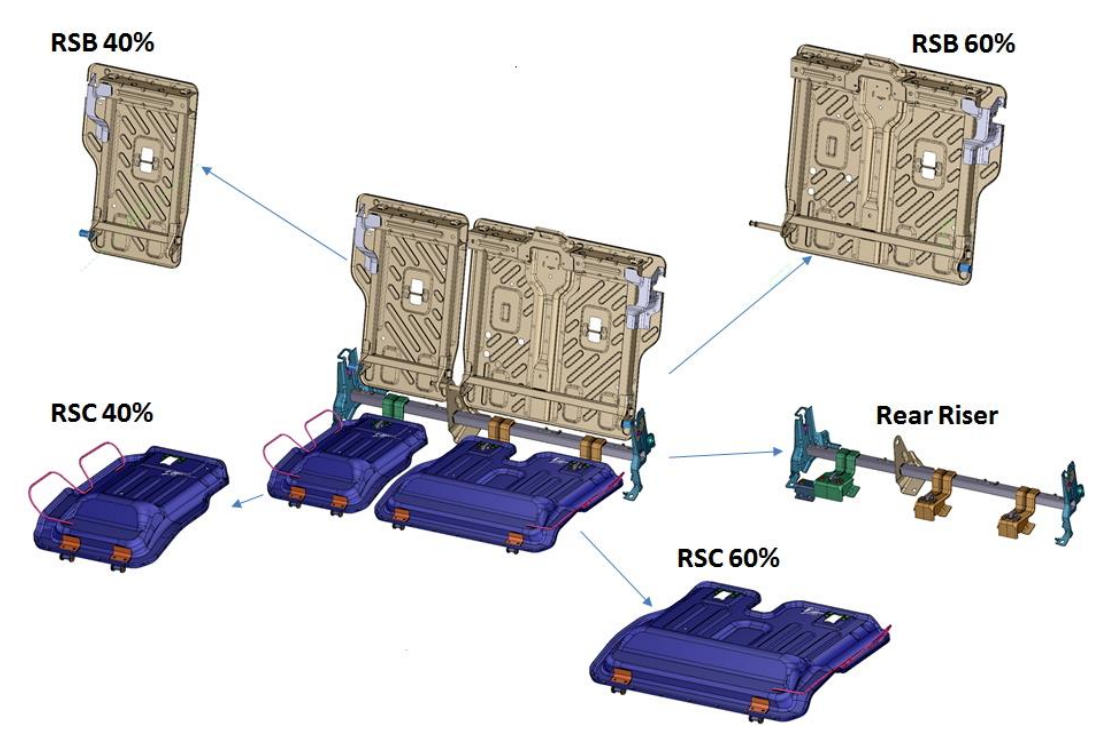

Figure 2 - Description of individual parts of the seat structure 


\section{Complex manufacturing process}

A complex manufacturing process consists of a number of simple manufacturing processes, either in time or in content. It is introduced in companies to maximize time efficiency on machines. This process is characterized by high quality requirements as well as flawless coordination of work, which is successively linked and last but not least, it has high requirements for organization. Each machine product is divided into separate parts [3].

All complex machinery products consist of individual groups, which are subgroups, subgroups formed from parts, and parts from two or more components.

Part - forms the basis of the product. It is the simplest piece of product and is made of only one piece of material without assembly.

Segment - is made up of several components that are connected with detachable or non-detachable joints.

Subgroup - consists of two or more parts and components, regardless of the type and method of storage.

Group - consists of two or more subgroups and does not look at their storage.

Assembly - from the functional or assembly point of view, it is the part of the product that is separate.

Product - it is already the final product that we can offer to the consumer market to meet their needs. It is, of course, composed of individual assemblies or assemblies, sub-assemblies, parts and components [4].

\subsection{Manufacturing process solution}

We begin to solve the complex manufacturing process of the rear seat structure by drawing up the production diagram of our seat (Figure 3).

First, you need to write down each operation in a table and assign time units in seconds (Table 1).

Table 1 - Operation data

\begin{tabular}{cccc}
\hline serial num. & section & part designation & $\mathrm{t}(\mathrm{s})$ \\
\hline $\mathbf{1 .}$ & product & $\mathrm{V}$ & 128 \\
$\mathbf{2}$. & assembly & $\mathrm{MC1}$ & 64 \\
$\mathbf{3 .}$ & segment & $\mathrm{D} 11$ & 32 \\
$\mathbf{4 .}$ & part & $\mathrm{S} 111$ & 8 \\
$\mathbf{5 .}$ & part & $\mathrm{S} 112$ & 6 \\
$\mathbf{6 .}$ & segment & $\mathrm{D} 12$ & 32 \\
7. & part & $\mathrm{S} 121$ & 7 \\
\hline
\end{tabular}




\begin{tabular}{|c|c|c|c|}
\hline 8. & part & S122 & 5 \\
\hline 9. & assembly & MC2 & 64 \\
\hline 10. & segment & D21 & 32 \\
\hline 11. & part & S211 & 8 \\
\hline 12. & part & $\mathrm{S} 212$ & 6 \\
\hline 13. & segment & D22 & 32 \\
\hline 14. & part & S221 & 7 \\
\hline 15. & part & S222 & 5 \\
\hline 16. & part & S311 & 9 \\
\hline 17. & part & S312 & 8 \\
\hline 18. & part & S313 & 8 \\
\hline 19. & part & S314 & 14 \\
\hline 20. & part & S315 & 11 \\
\hline
\end{tabular}

Our production workplace is assembling product $\mathrm{V}$. This product consists of two assemblies MC1 and MC2. Each assembly consists of two additional parts D11, D12 and D21, D22. The individual parts consist again of each of the two parts designated S111, S112, S121, S122, S211, S212, S221 and S222. In our specific case, components S311 to S315 enter straight into the final phase of the product. The sum of all times is calculated by adding up the times of individual operations and denoted by $\mathrm{T}^{\prime}$. The value of $\mathrm{T}^{\prime}$ came out for $486 \mathrm{~s}$.

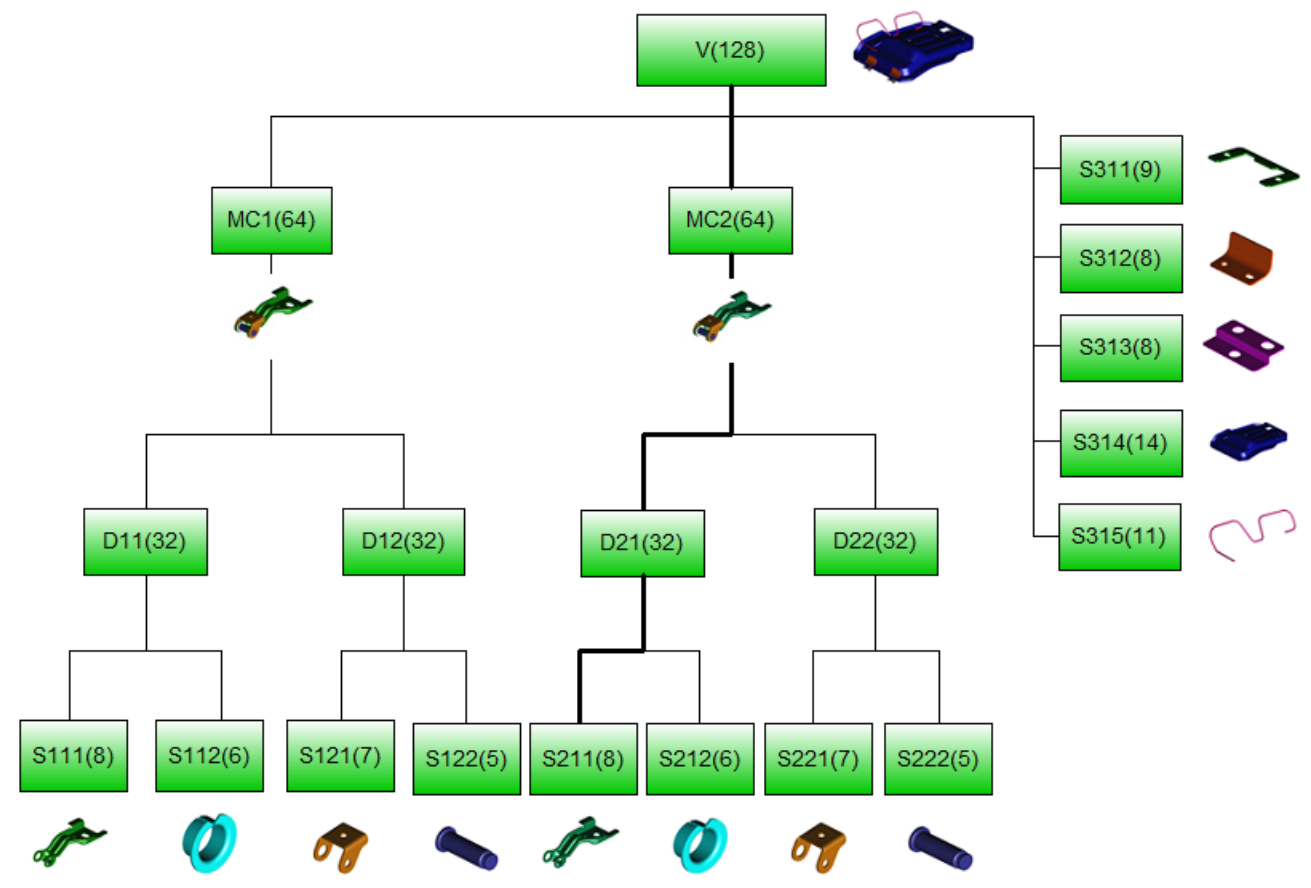

Figure 3 - Production - assembly diagram of the rear seat

From the production-assembly diagram we can see how many parts our product consists of, which parts enter straight into the final operation, where a complete rear seat is created. On the given scheme we mark the path of the 
longest branch, if we have two or more branches of the same length, we choose the longer one. This way, we calculate the running time of our rear seat construction.

\section{Running time of assembly:}

was calculated by summing the times of the individual operations, which consist of the longest branch that we have identified in the production-assembly diagram (1).

Calculation:

$$
\begin{gathered}
\mathrm{T}=\mathrm{Tm}+\Sigma \mathrm{ti} \mathrm{MC} 2+\Sigma \mathrm{ti} \mathrm{D} 21+\Sigma \mathrm{ti} \mathrm{S} 211 \\
\mathrm{~T}=\mathrm{V}+\mathrm{MC} 2+\mathrm{D} 21+\mathrm{S} 211 \\
\mathrm{~T}=128+64+32+8 \\
\mathrm{~T}=232 \mathrm{~s}
\end{gathered}
$$

\section{Calculation of $\alpha$ - coefficient of concurrency:}

$\alpha$ - coefficient of concurrence otherwise called also the concurrent concurrence of assembly processes is calculated as the ratio of the sum of all operation times $T^{\prime}$ to the average assembly time $T(2)$.

$$
\begin{gathered}
\alpha s t r=T^{\prime} / \mathrm{T} \\
\alpha s t r=486 / 232 \\
\alpha s t r=2,1 \mathrm{~s}
\end{gathered}
$$

After calculating the necessary running times and compiling the product assembly diagram, we use the obtained data to create a tree diagram (chronogram) (Figure 4). In the flow chart we find out how long we have the total production, in which the times of individual partial operations for the total production of the finished product are represented. We can also use this diagram to plan the beginnings of individual operations during production and to plan the simultaneous and continuous flow of material through production to avoid downtime or dead spots and minimize time reserves.

Through the overlapping diagram we can find out how many parts we have in the production process, whether how many concurrent operations are taking place at the time in production [5] [6] [7]. 


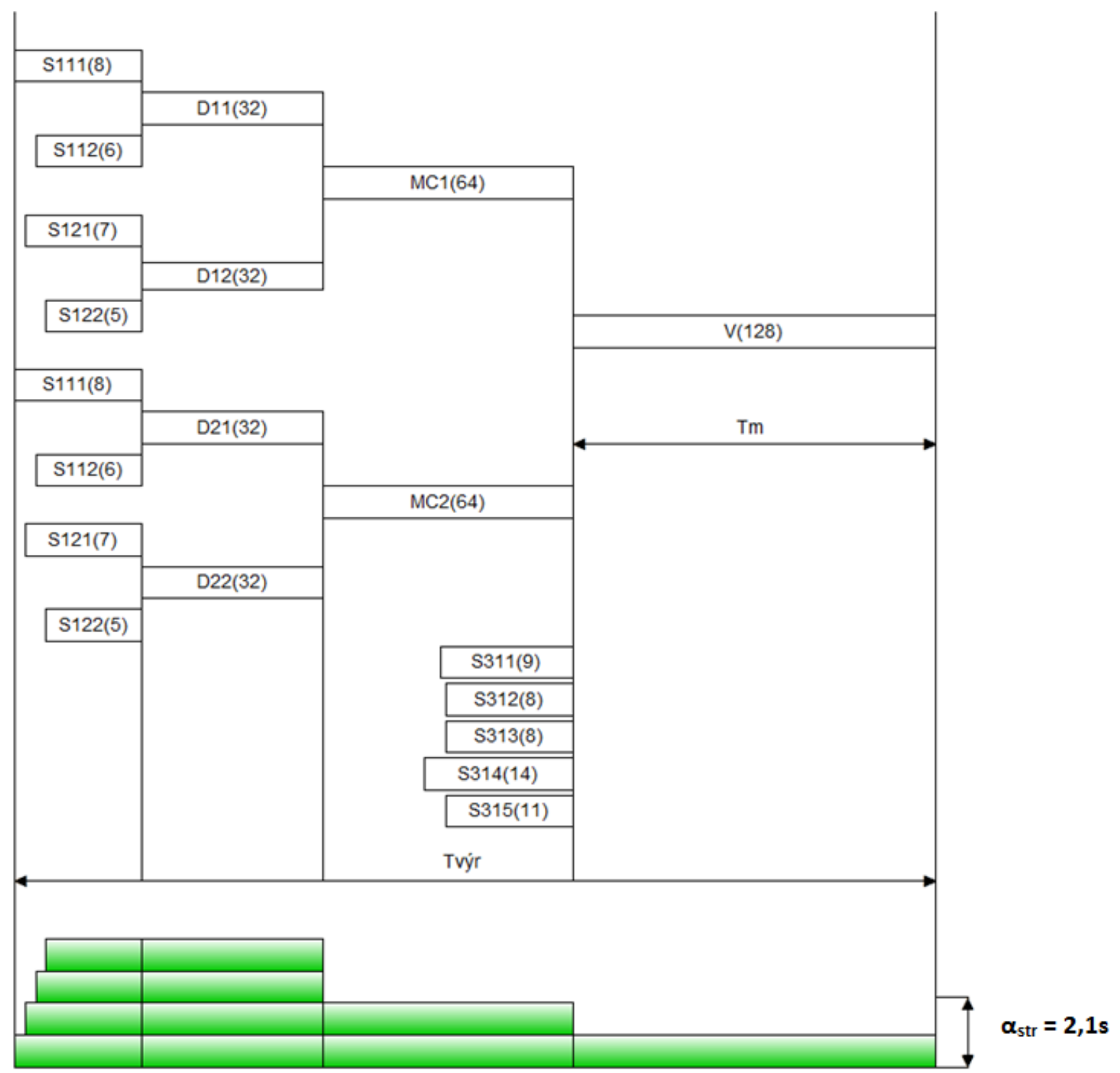

Figure 4 - Overlap and flow diagrams

\section{Conclusion}

In the present paper we described the individual parts of the rear seat structure for a Ford car. Our product was a production process according to a complicated production process, therefore we started to solve it by means of a production assembly diagram that contains data of operations. Through the longest branch we calculated the mounting time of our rear seat construction. We then calculated the coefficient of concurrency. Finally, we created a tree diagram (chronogram) in which we found out the length of the total production, the times of partial operations and what is their representation in the total production time of the finished product. The compilation of this diagram allows us to more easily plan the simultaneous and continuous flow of material through production, as well as help us build a simulation model of production through software. 


\section{Acknowledgment}

This article was created by implementation of the grant projects VEGA 1/0708/16 "Development of a new research methods for simulation, assessment, evaluation and quantification of advanced methods of production", KEGA 030TUKE-4/2017 Implementation of innovative instruments for increasing the quality of higher education in the 5.2 .52 Industrial engineering field of study and APVV-17-0258 Digital engineering elements application in innovation and optimization of production flows.

\section{References}

[1] Markulik Š., Cehlár M., Kozel R. Process approach in the mining conditions. In: Acta Montanistica Slovaca, 2018, vol. 23, no. 1, p. 46-52. ISSN 13351788.

[2] Poor, P., Basl, J. Czech Republic and Processes of Industry 4.0 Implementation. In: Proceedings of the $29^{\text {th }} D A A A M$ International Symposium, Vienna, Austria, 2018, p.454-459. ISBN 978-3-902734-20-4, ISSN 17269679.

[3] Kłos, S. Implementation of the AHP method in ERP-based decision support systems for a new product development. In: Communications in Computer and Information Science, 2015. ISSN 1865-0929.

[4] Kliment, M., Popovič, R., Janek, J. Analysis of the Production Process in the Selected Company and Proposal a Possible Model Optimization Through PLM Software Module Tecnomatix Plant Simulation. In: Procedia Engineering: Modelling of Mechanical and Mechatronic Systems MMaMS, 2014, vol. 96, p. 221-226. ISSN 1877-7058.

[5] Straka, M., Lenort, R., Khouri, S., Feliks, J. Design of large-scale logistics systems using computer simulation hierarchic structure. In: International Journal of Simulation Modelling, 2018, vol. 17, no. 1, p. 105-118.

[6] Trebuňa, P., Kliment, M., Edl, M., Petrik, M. Creation of Simulation Model of Expansion of Production in Manufacturing Companies. In: Procedia Engineering: Modelling of Mechanical and Mechatronic Systems MMaMS, 2014, vol. 96, p. 477-482. ISSN 1877-7058.

[7] Edl, M., Lerher, T., Rosi, B. Energy efficiency model for the mini-load automated storage and retrieval systems. In: International Journal of Advanced Manufacturing Technology, 2013, p. 1-19. ISSN 0268-376. 